\title{
Physical function as a prognostic biomarker among cancer survivors
}

\author{
J C Brown*,1, M O Harhay ${ }^{1}$ and M N Harhay ${ }^{1,2}$ \\ ${ }^{1}$ Center for Clinical Epidemiology and Biostatistics, University of Pennsylvania School of Medicine, 423 Guardian Drive, 8th Floor, \\ Blockley Hall, Philadelphia, PA 19104, USA and ${ }^{2}$ Renal-Electrolyte and Hypertension Division, University of Pennsylvania School of \\ Medicine, Philadelphia, PA 19104, USA
}

Background: We tested the hypothesis that objectively measured physical function predicts mortality among cancer survivors.

Methods: We assessed objectively measured physical function including the short physical performance battery (SPPB) and fast walk speed in older adult cancer survivors.

Results: Among 413 cancer survivors, 315 (76\%) died during a median follow-up of 11.0 years. In multivariable-adjusted analyses, each 1-unit increase in the SPPB score and $0.1 \mathrm{~ms}^{-1}$ increase in fast walk speed predicted a $12 \%$ reduction in mortality (hazard ratio (HR): 0.88 (95\% confidence interval (Cl): 0.82-0.94); $P<0.001$, and HR: 0.88 (95\% Cl: 0.82-0.96); $P=0.003$, respectively).

Conclusions: Objectively measured physical function may predict mortality among cancer survivors.

Despite improvements in cancer survival rates (DeSantis et al, 2014), cancer survivors frequently experience deleterious sequela resulting from treatment including impairments in the cardiovascular, pulmonary, neurologic, and musculoskeletal systems (Jones et al, 2009). Normally, these physiologic systems work in concert to enable physical function, and when one system is compromised, other systems may compensate (Dickinson et al, 2000, Ferrucci et al, 2000). However, when multiple physiologic systems are simultaneously compromised, patients are more likely to manifest impairments in physical function (Ferrucci et al, 2000), resulting in increased susceptibility to adverse health outcomes, such as premature mortality (Guralnik et al, 1994; Studenski et al, 2011). In this context, quantifying physical function status after cancer treatment may provide important insights to clinicians on the health, vitality, and prognosis of cancer survivors.

We tested the hypothesis that objectively measured physical function metrics, including the short physical performance battery (SPPB; Guralnik et al, 1994) and fast walk speed (Studenski et al, 2011), are capable of quantifying health and vitality by prognosticating premature mortality among a population-based sample of cancer survivors.

\section{MATERIALS AND METHODS}

Study design. The Third National Health and Nutrition Examination Survey, 1988-1994 (NHANES III), was a stratified multistage study designed to provide health information on a nationally representative sample of civilians living within the United States (Center for Disease Control, 1994). All participants provided written informed consent before participating in any study-related activities.

Study participants. Participants aged $\geqslant 60$ years were invited to complete an evaluation that included objective measures of physical function (Ostchega et al, 2000). We identified 4809 participants who completed the requisite physical function measures, 413 (9\%) of whom reported a prior diagnosis of nonskin-related cancer.

Objective measures of physical function. The physical function exam used in NHANES III was a modified version of the SPPB (Ostchega et al, 2000). The SPPB is a series of three objective measures that quantify balance, lower-extremity strength, and gait among older adults (Guralnik et al, 1994). Each of the three SPPB

*Correspondence: JC Brown; E-mail: brownjus@mail.med.upenn.edu

Received 11 July 2014; revised 20 September 2014; accepted 12 October 2014; published online 13 November 2014

(c) 2015 Cancer Research UK. All rights reserved 0007-0920/15 
Table 1. Demographic and clinical characteristics, stratified by survival status ${ }^{a}$

Died during follow-up

\begin{tabular}{|c|c|c|c|c|}
\hline Characteristics & $\begin{array}{l}\text { Overall }(n=413)(\text { mean } \\
(\text { s.e.) or } n(\%))\end{array}$ & Yes $(n=315)$ & No $(n=98)$ & $P$-value \\
\hline Age (years) & $72.2(0.47)$ & $74.4(0.56)$ & $66.9(0.61)$ & $<0.001$ \\
\hline Sex & & & & $<0.001$ \\
\hline $\begin{array}{l}\text { Male } \\
\text { Female }\end{array}$ & $\begin{array}{l}40.0 \% \\
60.0 \%\end{array}$ & $\begin{array}{l}48.4 \% \\
51.6 \%\end{array}$ & $\begin{array}{l}19.5 \% \\
80.5 \%\end{array}$ & \\
\hline Type of cancer & & & & 0.012 \\
\hline $\begin{array}{l}\text { Breast } \\
\text { Genitourinary } \\
\text { Gastrointestinal } \\
\text { Gynaecologic } \\
\text { Lung } \\
\text { Haematologic } \\
\text { Other, missing, or cannot remember }\end{array}$ & $\begin{array}{c}26.6 \% \\
20.7 \% \\
18.4 \% \\
13.7 \% \\
3.4 \% \\
2.5 \% \\
14.7 \%\end{array}$ & $\begin{array}{c}24.4 \% \\
24.0 \% \\
19.6 \% \\
10.3 \% \\
4.8 \% \\
1.5 \% \\
15.3 \%\end{array}$ & $\begin{array}{c}31.8 \% \\
12.4 \% \\
15.4 \% \\
21.9 \% \\
0.0 \% \\
5.0 \% \\
13.4 \%\end{array}$ & \\
\hline \multicolumn{5}{|l|}{ Time since cancer diagnosis (years) } \\
\hline $\begin{array}{l}\text { Mean (continuous) } \\
<5 \\
5-10 \\
\geqslant 10\end{array}$ & $\begin{array}{c}10.7(0.64) \\
35.5 \% \\
21.9 \% \\
42.6 \%\end{array}$ & $\begin{array}{c}10.1(0.70) \\
37.1 \% \\
23.2 \% \\
39.7 \%\end{array}$ & $\begin{array}{c}12.3(1.39) \\
31.5 \% \\
18.7 \% \\
49.8 \%\end{array}$ & $\begin{array}{l}0.151 \\
0.361\end{array}$ \\
\hline \multicolumn{5}{|l|}{ Body mass index $\left(\mathrm{kg} \mathrm{m}^{-2}\right)$} \\
\hline $\begin{array}{l}\text { Mean (continuous) } \\
<18.5 \\
18.5-24.9 \\
25.0-29.9 \\
\geq 30.0\end{array}$ & $\begin{array}{c}25.8(0.30) \\
3.1 \% \\
43.8 \% \\
35.1 \% \\
18.0 \%\end{array}$ & $\begin{array}{c}25.7(0.35) \\
4.4 \% \\
42.6 \% \\
35.0 \% \\
18.0 \%\end{array}$ & $\begin{array}{c}26.1(0.59) \\
0.0 \% \\
46.6 \% \\
35.4 \% \\
18.0 \%\end{array}$ & $\begin{array}{l}0.554 \\
0.380\end{array}$ \\
\hline \multicolumn{5}{|l|}{ Smoking status, $n(\%)$} \\
\hline $\begin{array}{l}\text { Never } \\
\text { Former } \\
\text { Current }\end{array}$ & $\begin{array}{l}43.4 \% \\
45.4 \% \\
11.2 \%\end{array}$ & $\begin{array}{l}43.0 \% \\
46.8 \% \\
10.2 \%\end{array}$ & $\begin{array}{l}44.5 \% \\
42.0 \% \\
13.5 \%\end{array}$ & 0.703 \\
\hline Healthy eating index & $69.6(0.86)$ & $68.2(0.96)$ & $72.5(1.73)$ & 0.035 \\
\hline No. of alcoholic drinks consumed in past week & $1.1(0.15)$ & $0.9(0.16)$ & $1.6(0.31)$ & 0.046 \\
\hline \multicolumn{5}{|l|}{ Comorbid health conditions } \\
\hline $\begin{array}{l}\text { Hypertension } \\
\text { Diabetes } \\
\text { Hyperlipidaemia } \\
\text { Asthma } \\
\text { Arthritis } \\
\text { Myocardial infarction } \\
\text { Stroke } \\
\text { Congestive heart failure }\end{array}$ & $\begin{array}{c}46.4 \% \\
10.3 \% \\
33.8 \% \\
6.3 \% \\
44.8 \% \\
15.3 \% \\
6.7 \% \\
6.2 \%\end{array}$ & $\begin{array}{c}46.0 \% \\
12.4 \% \\
28.9 \% \\
8.0 \% \\
45.1 \% \\
20.0 \% \\
8.6 \% \\
7.1 \%\end{array}$ & $\begin{array}{c}47.2 \% \\
5.3 \% \\
45.9 \% \\
2.2 \% \\
44.0 \% \\
4.0 \% \\
2.1 \% \\
4.1 \%\end{array}$ & $\begin{array}{r}0.872 \\
0.110 \\
0.014 \\
0.108 \\
0.878 \\
<0.001 \\
0.023 \\
0.367\end{array}$ \\
\hline Hospitalisation(s) in past year, $n(\%)$ & $29.1 \%$ & $31.5 \%$ & $23.2 \%$ & 0.211 \\
\hline Haemoglobin $\left(\mathrm{g} \mathrm{dl}^{-1}\right)$ & $13.5(0.08)$ & $13.6(0.10)$ & $13.5(0.13)$ & 0.702 \\
\hline Albumin $\left(\mathrm{g} \mathrm{dl}^{-1}\right)$ & $4.0(0.02)$ & $4.0(0.02)$ & $4.1(0.04)$ & 0.271 \\
\hline C-reactive protein $\left(\mathrm{mgl}^{-1}\right)$ & $0.6(0.05)$ & $0.6(0.06)$ & $0.4(0.08)$ & 0.031 \\
\hline Self-reported health & $50.1(1.78)$ & $45.9(1.97)$ & $60.5(3.42)$ & $<0.001$ \\
\hline \multicolumn{5}{|l|}{ No. of bouts of walking in past week } \\
\hline $\begin{array}{l}0 \\
1-3 \\
\geqslant 3\end{array}$ & $\begin{array}{c}74.3 \% \\
7.6 \% \\
18.1 \%\end{array}$ & $\begin{array}{c}80.5 \% \\
5.7 \% \\
13.8 \%\end{array}$ & $\begin{array}{l}59.2 \% \\
12.2 \% \\
28.6 \%\end{array}$ & 0.004 \\
\hline \multicolumn{5}{|l|}{ Short physical performance battery } \\
\hline $\begin{array}{l}\text { Mean (continuous) } \\
\leqslant 6 \\
7-9 \\
\geqslant 10\end{array}$ & $\begin{array}{c}9.1(0.14) \\
13.9 \% \\
33.6 \% \\
52.5 \%\end{array}$ & $\begin{array}{c}8.6(0.18) \\
18.5 \% \\
35.8 \% \\
45.7 \%\end{array}$ & $\begin{array}{c}10.2(0.20) \\
2.6 \% \\
28.1 \% \\
69.3 \%\end{array}$ & $\begin{array}{l}<0.001 \\
<0.001\end{array}$ \\
\hline \multicolumn{5}{|l|}{ Fast walk speed $\left(\mathrm{ms}^{-1}\right)$} \\
\hline $\begin{array}{l}\text { Mean (continuous) } \\
<0.6 \\
\geqslant 0.6\end{array}$ & $\begin{array}{c}0.72(0.01) \\
26.7 \% \\
73.3 \% \\
\end{array}$ & $\begin{array}{l}0.67(0.02) \\
34.1 \% \\
65.9 \% \\
\end{array}$ & $\begin{array}{c}0.82(0.02) \\
8.5 \% \\
91.5 \% \\
\end{array}$ & $\begin{array}{l}<0.001 \\
<0.001\end{array}$ \\
\hline
\end{tabular}


measures is scored from 0 to 4 , with higher scores indicating greater physical function. Each of the three individual SPPB scores is aggregated to derive a summary SPPB score, ranging from 0 to 12, with higher scores indicating greater physical function. Modifications to the SPPB used in NHANES III did not include the side-by-side and semi-tandem balance tests (assessing only fulltandem balance), and measured gait speed at a pace twice that of the usual walking speed ( $v s$ usual speed), referred to herein as fast walk speed. Fast walk speed alone has been shown to predict outcomes similarly to the full SPPB battery (Guralnik et al, 2000). Therefore, in addition to examining the prognostic relationship between the SPPB and mortality, we also examined the prognostic relationship between fast walk speed alone and mortality. Fast walk speed was quantified in units of $\mathrm{ms}^{-1}$. Additional information about the objective measures of physical function is provided in the online Supplementary Methods.

Mortality outcome. The primary outcome of this study was allcause mortality. Vital status was identified using the National Death Index database through 31 December 2006 (National Center for Health Statistics, 2006). Additional information about the mortality outcome is provided in the online Supplementary Methods.

Covariates. Detailed information for all study covariates is provided in the online Supplementary Methods.

Statistical analysis. We fit Cox proportional hazards regression models to estimate the hazard ratio (HR) and 95\% confidence interval (CI) for all-cause mortality by varying levels of physical function.

The SPPB score was examined as a categorical and continuous variable in separate regression models. The categorical SPPB score variable classified participants into one of three groups: $\leqslant 6,7-9$, and $\geqslant 10$, to denote increasing levels of physical function, respectively. This categorisation schema predicts limitations in activities of daily living and mobility-related disability among older adults (Guralnik et al, 1995). The continuous SPPB score is presented for each 1-unit increase to reflect a clinically meaningful change in physical function (Perera et al, 2006).

Fast walk speed was examined as a categorical and continuous variable in separate regression models. The categorical fast walk speed variable classified participants into one of two groups: $<0.6 \mathrm{~m} \mathrm{~s}^{-1}$ or $\geqslant 0.6 \mathrm{~m} \mathrm{~s}^{-1}$ to denote slow and fast walk speed, respectively. This categorisation schema predicts dependency in activities of daily living, self-reported health status, and frequency of hospitalisation among older adults (Studenski et al, 2003). The continuous fast walk speed variable is presented for each $0.1 \mathrm{~m} \mathrm{~s}^{-1}$ increase, which is acknowledged to reflect a clinically meaningful change in physical function (Perera et al, 2006). Additional information about the statistical analysis is provided in the online Supplementary Methods.

\section{RESULTS}

Characteristics associated with mortality. Among 413 cancer survivors, we observed 315 deaths during a median of 11.0 years of follow-up. Participant characteristics are depicted overall and stratified by vital status (Table 1).

Objective physical function and all-cause mortality. Median survival was 10.5 and 13.4 years in the groups with an SPPB score of $7-9$ and $\geqslant 10$, respectively, as compared with 5.0 years in the group with an SPPB score of $\leqslant 6$ (Figure 1A). In multivariableadjusted analyses, an SPPB score of $7-9$ and $\geqslant 10$ predicted a $43 \%$ (HR: 0.57 (95\% CI: 0.37-0.89); $P=0.014$ ) and a 50\% (HR: 0.50 (95\% CI: $0.32-0.77) ; P=0.001)$ reduction in the risk of premature mortality, relative to an SPPB score of $\leqslant 6$ (Table 2). As a
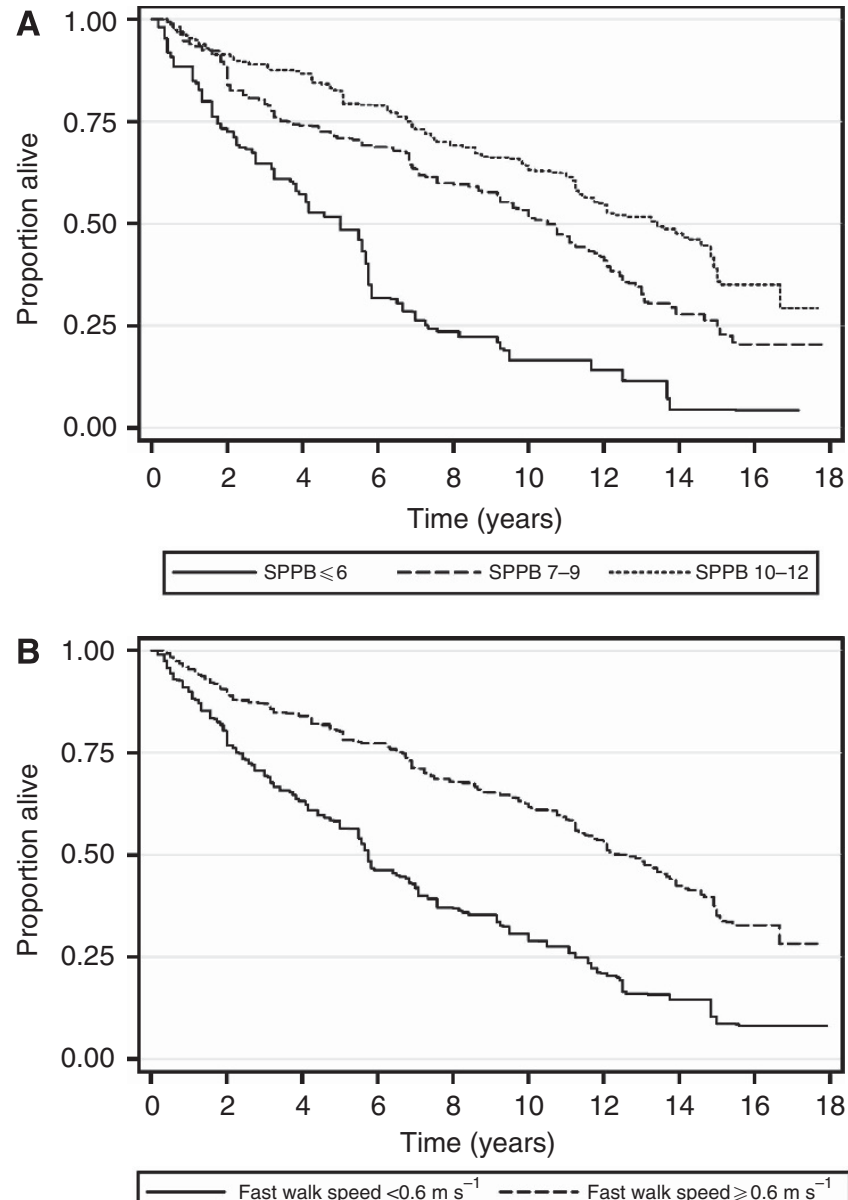

Figure 1. Kaplan-Meier survival plot, stratified by Category of Physical Function for (A) short physical performance battery (SPPB) and (B) fast walk speed.

continuous variable, each 1-unit increase in the SPPB score predicted a $12 \%$ reduction in the risk of premature mortality (HR: 0.88 (95\% CI: $0.82-0.94) ; P<0.001$ ).

Median survival was 12.6 years in the group with a fast walk speed $\geqslant 0.6 \mathrm{~m} \mathrm{~s}^{-1}$, as compared with 5.8 years in the group with a fast walk speed $<0.6 \mathrm{~m} \mathrm{~s}^{-1}$ (Figure 1B). In multivariable-adjusted analyses, a fast walk speed $\geqslant 0.6 \mathrm{~m} \mathrm{~s}^{-1}$ predicted a $34 \%$ reduction in the risk of premature mortality, relative to a fast walk speed $<0.6 \mathrm{~m} \mathrm{~s}^{-1}$ (HR: 0.66 (95\% CI: 0.47-0.93); $P=0.019$ ). As a continuous variable, each $0.1 \mathrm{~m} \mathrm{~s}^{-1}$ increase in fast walk speed predicted a $12 \%$ reduction in the risk of premature mortality (HR: 0.88 (95\% CI: 0.82-0.96); $P=0.003$ ).

The tests of interaction between objective physical function and mortality by cancer type are provided in the online Supplementary Results. The discriminative capacity of objective physical function to predict 5- and 10-year mortality is provided in the online Supplementary Results.

\section{DISCUSSION}

The principal finding of this study is that cancer survivors with higher levels of physical function are less likely to die prematurely, relative to cancer survivors with lower levels of physical function. Our findings provide evidence that objectively measured physical function may be a useful biomarker to quantify the health and vitality of cancer survivors by prognosticating premature mortality. 
Table 2. Association between physical function and all-cause mortality

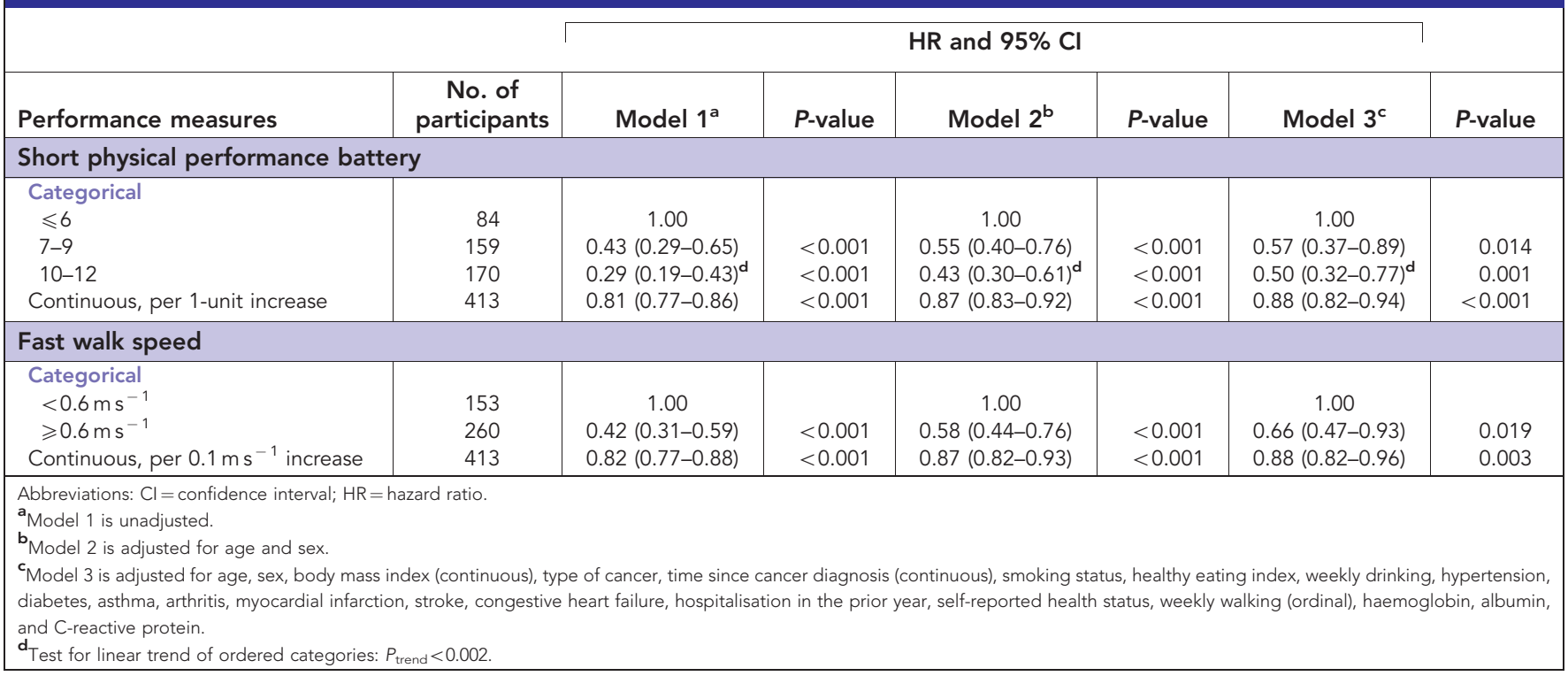

Lifestyle behaviour modification such as physical activity, weight loss, and eating a healthful diet may preserve or improve the physiologic systems necessary to sustain physical function. Participation in physical activity preserves fast walk speed, improves SPPB, and delays the onset of major mobility disability among older adults (LIFE Study Investigators et al, 2006, Pahor et al, 2014). Coupled with physical activity, weight loss and eating a healthful diet are efficacious to improve physical function among older breast, prostate, and colon cancer survivors (Demark-Wahnefried et al, 2006; Morey et al, 2009). The promotion of lifestyle behaviours that include physical activity, weight management, and healthful eating are important among cancer survivors, as they may translate to improvements in patientreported and clinical outcomes (Demark-Wahnefried et al, 2012; Rock et al, 2012).

One weakness of this study is the absence of information in this cohort relating to the stage of cancer and type of treatment received. A second weakness is the use of self-reported clinical and comorbidity information. Inaccurate clinical information or undiagnosed comorbidity may bias our results. For example, it has been reported that for each known case of diabetes, there exists one undiagnosed case (Dunstan et al, 2002). A third weakness is the limited sample size of cancer-specific subgroups. Future studies will require larger samples to examine the prognostic impact of physical function among cancer-specific subgroups. Although it is unlikely that stage of cancer or type of treatment interact with the prognostic importance of physical function (Klepin et al, 2010; Cesari et al, 2013), we had insufficient data to corroborate this finding in our data set. A fourth weakness is that physical function was a cross-sectional measurement in this cohort. Declines in longitudinally measured self-reported physical function associate with mortality among breast cancer survivors (Sehl et al, 2013). Conversely, a major strength of this study was the populationbased sampling framework of NHANES, which permitted our analyses to represent community-dwelling older adult cancer survivors in the United States.

In conclusion, physical function, quantified using the SPPB or fast walk speed, is a prognostic biomarker among older adult cancer survivors. This finding is consistent with the hypothesis that physical function possesses the capacity to synchronously describe the performance and coordination of various physiologic systems that may be impaired as a result of cancer treatment. Additional work is necessary to confirm the prognostic importance of this biomarker among cancer survivors and to establish an evidence base to support integrating physical function measures in the oncologic standard of care.

\section{ACKNOWLEDGEMENTS}

MNH has received training grants (5T32DK007006 and F32DK096758) from the National Institute of Diabetes and Digestive and Kidney Diseases. $\mathrm{MOH}$ is supported as a predoctoral fellow by National Cancer Institute (NCI) grant R01CA159932. JCB is supported as a pre-doctoral fellow by NCI grants U54CA155850 and R21CA182767.

\section{CONFLICT OF INTEREST}

The authors declare no conflict of interest.

\section{REFERENCES}

Cesari M, Cerullo F, Zamboni V, Di Palma R, Scambia G, Balducci L, Incalzi RA, Vellas B, Gambassi G (2013) Functional status and mortality in older women with gynecological cancer. J Gerontol A Biol Sci Med Sci 68(9): 1129-1133.

Center for Disease Control (1994) Plan and Operation of the Third National Health and Nutrition Examination Survey, 1988-94. Series 1: Programs and Collection Procedures. Vital Health Stat 1(32): 1-407.

Demark-Wahnefried W, Clipp EC, Morey MC, Pieper CF, Sloane R, Snyder DC, Cohen HJ (2006) Lifestyle intervention development study to improve physical function in older adults with cancer: outcomes from Project LEAD. J Clin Oncol 24: 3465-3473.

Demark-Wahnefried W, Platz EA, Ligibel JA, Blair CK, Courneya KS, Meyerhardt JA, Ganz PA, Rock CL, Schmitz KH, Wadden T, Philip EJ, Wolfe B, Gapstur SM, Ballard-Barbash R, McTiernan A, Minasian L, Nebeling L, Goodwin PJ (2012) The role of obesity in cancer survival and recurrence. Cancer Epidemiol Biomarkers Prev 21: 1244-1259.

DeSantis CE, Lin CC, Mariotto AB, Siegel RL, Stein KD, Kramer JL, Alteri R, Robbins AS, Jemal A (2014) Cancer treatment and survivorship statistics, 2014. CA Cancer J Clin 64(4): 252-271.

Dickinson MH, Farley CT, Full RJ, Koehl MA, Kram R, Lehman S (2000) How animals move: an integrative view. Science 288: 100-106.

Dunstan DW, Zimmet PZ, Welborn TA, De Courten MP, Cameron AJ, Sicree RA, Dwyer T, Colagiuri S, Jolley D, Knuiman M, Atkins R, Shaw JE (2002) The 
rising prevalence of diabetes and impaired glucose tolerance: the Australian Diabetes, Obesity and Lifestyle Study. Diabetes Care 25: 829-834.

Ferrucci L, Bandinell S, Benvenuti E, Di Iorio A, Macchi C, Harris T, Guralnik JM (2000) Subsystems contributing to the decline in ability to walk: bridging the gap between epidemiology and geriatric practice in the InCHIANTI study. J Am Geriatr Soc 48: 1618-1625.

Guralnik JM, Ferrucci L, Pieper CF, Leveille SG, Markides KS, Ostir GV, Studenski S, Berkman LF, Wallace RB (2000) Lower extremity function and subsequent disability consistency across studies, predictive models, and value of gait speed alone compared with the Short Physical Performance Battery. J Gerontol A Biol Sci Med Sci 55: M221-M231.

Guralnik JM, Ferrucci L, Simonsick EM, Salive ME, Wallace RB (1995) Lower-extremity function in persons over the age of 70 years as a predictor of subsequent disability. $N$ Engl J Med 332: 556-562.

Guralnik JM, Simonsick EM, Ferrucci L, Glynn RJ, Berkman LF, Blazer DG, Scherr PA, Wallace RB (1994) A short physical performance battery assessing lower extremity function: association with self-reported disability and prediction of mortality and nursing home admission. J Gerontol 49: M85-M94.

Jones LW, Eves ND, Haykowsky M, Freedland SJ, Mackey JR (2009) Exercise intolerance in cancer and the role of exercise therapy to reverse dysfunction. Lancet Oncol 10: 598-605.

Klepin HD, Geiger AM, Tooze JA, Newman AB, Colbert LH, Bauer DC, Satterfield S, Pavon J, Kritchevsky SB (2010) Physical performance and subsequent disability and survival in older adults with malignancy: results from the health, aging and body composition study. J Am Geriatr Soc 58: $76-82$.

LIFE Study Investigators, Pahor M, Blair SN, Espeland M, Fielding R, Gill TM, Guralnik JM, Hadley EC, King AC, Kritchevsky SB, Maraldi C, Miller ME Newman AB, Rejeski WJ, Romashkan S, Studenski S (2006) Effects of a physical activity intervention on measures of physical performance: Results of the lifestyle interventions and independence for Elders Pilot (LIFE-P) study. J Gerontol A Biol Sci Med Sci 61: 1157-1165.

Morey MC, Snyder DC, Sloane R, Cohen HJ, Peterson B, Hartman TJ, Miller P, Mitchell DC, Demark-Wahnefried W (2009) Effects of home-based diet and exercise on functional outcomes among older, overweight long-term cancer survivors. JAMA 301: 1883-1891.
National Center for Health Statistics (2006) The Third National Nutrition and Health Survey Linked Mortality File: Matching Methodology. http://www. cdc.gov/nchs/data_access/data_linkage/mortality/nhanes3_linkage.htm.

Ostchega Y, Harris TB, Hirsch R, Parsons VL, Kington R, Katzoff M (2000) Reliability and prevalence of physical performance examination assessing mobility and balance in older persons in the US: data from the Third National Health and Nutrition Examination Survey. J Am Geriatr Soc 48: $1136-1141$.

Pahor M, Guralnik JM, Ambrosius WT, Blair S, Bonds DE, Church TS, Espeland MA, Fielding RA, Gill TM, Groessl EJ, King AC, Kritchevsky SB, Manini TM, McDermott MM, Miller ME, Newman AB, Rejeski WJ, Sink KM, Williamson JD. LIFE study investigators (2014) Effect of structured physical activity on prevention of major mobility disability in older adults: The life study randomized clinical trial. JAMA 311(23): 2387-2396.

Perera S, Mody SH, Woodman RC, Studenski SA (2006) Meaningful change and responsiveness in common physical performance measures in older adults. J Am Geriatr Soc 54: 743-749.

Rock CL, Doyle C, Demark-Wahnefried W, Meyerhardt J, Courneya KS, Schwartz AL, Bandera EV, Hamilton KK, Grant B, McCullough M, Byers T, Gansler T (2012) Nutrition and physical activity guidelines for cancer survivors. CA Cancer J Clin 62(4): 243-274.

Sehl M, Lu X, Silliman R, Ganz PA (2013) Decline in physical functioning in first 2 years after breast cancer diagnosis predicts 10-year survival in older women. J Cancer Surviv 7: 20-31.

Studenski S, Perera S, Patel K, Rosano C, Faulkner K, Inzitari M, Brach J, Chandler J, Cawthon P, Connor EB (2011) Gait speed and survival in older adults. JAMA 305: 50-58.

Studenski S, Perera S, Wallace D, Chandler JM, Duncan PW, Rooney E, Fox M, Guralnik JM (2003) Physical performance measures in the clinical setting. J Am Geriatr Soc 51: 314-322.

This work is published under the standard license to publish agreement. After 12 months the work will become freely available and the license terms will switch to a Creative Commons AttributionNonCommercial-Share Alike 3.0 Unported License.

Supplementary Information accompanies this paper on British Journal of Cancer website (http://www.nature.com/bjc) 